Syagnik (Sy) Banerjee is an Associate Professor of Marketing at University of Michigan-Flint. He graduated with a PhD in Marketing from University of Rhode Island and his research covers areas including effectiveness of mobile advertising, situated and ubiquitous consumer behaviour, social media listening, and location-based big data.

\section{Rishika Rishika}

is a Clinical Assistant Professor of Marketing at University of South Carolina. She graduated with a PhD in Marketing from University of California, Irvine, and her research interests include social media analytics, social media marketing, social contagion, pricing, new products, market analysis and response, new empirical industrial organization (NEIO), marketing, and public policy.

Keywords: mobile marketing, SMS, personalized advertising

\section{Global mobile device ownership}

\section{Rising media costs in mobile}

\footnotetext{
Syagnik (Sy) Banerjee,

Mobile \& Interactive Marketing,

School of Management, University of Michigan-Flint, Room 2128,

Riverfront Center W., Flint, MI 48502, USA

Tel: +1 4012433206

E-mail: syban@umflint.edu
}

\section{Papers}

\section{The art of mistiming: How interruptions make mobile coupon campaigns effective}

\author{
Syagnik (Sy) Banerjee and Rishika Rishika \\ Received (in revised form): 11th May 2015
}

\begin{abstract}
With the explosion of the mobile web, companies and brands are relying more and more on inbound marketing, focusing on generating dialogues and providing customers with more relevant and customized ad content. Interruptions, which were often used as attention-grabbing tactics, seem to be obsolete with rising privacy concerns. However, in this era of permission and relevance-based marketing, the authors conducted an SMS marketing field experiment with fast food brands to demonstrate how message design and targeting can drive interruptions via mobile devices to generate more awareness, redemptions and future purchase intentions of the brand.
\end{abstract}

Journal of Direct, Data and Digital Marketing Practice (2015) 17, 101-113. doi:10.1057/dddmp.2015.43

\section{Introduction}

Digital advertising and marketing are expected to lead the growth in global media spend over the next few years and nearly reach the levels of television ad spending. The global mobile device ownership of 6.9 billion and penetration level of 95.5 per cent have clearly boosted internet usage and advertising beyond expectations. The ubiquitous penetration of mobile devices has made marketing capabilities pervasive not only in terms of reach, but also in terms of collecting consumer data. This has raised privacy concerns from watchdogs, regulatory bodies and consumers who feel irritated because of interruptions in their lives by sales calls while they are engaged with other important tasks.

In order to preserve the value of mobile as a medium of personal communication as well as consumption, industries have carefully governed the boundaries between their capabilities of reach and consumers' privacy needs. As a result, most marketers have focused on customizing the content and timing of campaigns suited to the user, seeking permission and soliciting dedicated attention to relevant marketing content. Concerned with falling attention spans and increasing cost per mile and cost per click (costs of media exposure), marketers have tried to maximize engagement as the primary measure of advertising effectiveness. But when all advertisers design relevant content and reach the same set of 
Interruption still has value

\section{Context and relevance}

\section{Creepy interruptions}

\section{Interruption can be memorable}

eyeballs with inbound marketing, dedicated attention and engagement become difficult to capture.

Departing from these current industry norms, this paper explores the effect of interrupting or distracting consumers who are busy at some other task, generating passing or partial attention towards the ad. We demonstrate with a field experiment that interruptions can still drive higher effectiveness on a loyal customer base if no demands of immediacy are imposed on the consumer, depending on how messages are framed.

Findings show that coupons lead to higher actual redemptions and memory if the campaign message interrupted the consumer when they were actively engaged with other tasks. The implications for digital, direct and relevant marketing practices are further discussed.

\section{Literature review}

Context is the key to the kingdom of the digital marketing space. Out of the expected US\$10.15 bn spend on mobile advertising in the United States, over 40 per cent is expected to be spent on context-aware or location-based mobile advertising. ${ }^{1}$ Targeting context-aware advertisements helps companies improve campaign attribution, that is, tying conversions to specific ad campaigns, and also increases marketers' tendencies to deliver relevance and convenience value based on geographic proximity. ${ }^{2}$

Relevance in the marketers' dictionary not only indicates geographical proximity, but also blending in, that is, fitting content to co-occurring ongoing activities or situations. Thus, logic suggests that interruptions, which are defined as 'externally generated randomly occurring, discrete events that break continuity of cognitive focus on a primary task ${ }^{3}$ (p. 12) should create attentional distractions, ${ }^{4}$ and negatively affect consumers' ability to perform their primary tasks, and intention towards making any immediate purchase transactions. Prior research finds that interruptions can lead to increased ad avoidance $e^{5,6}$ as well as lower willingness to pay for the

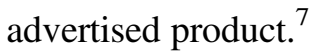

Though fitting in with context can positively influence decision making, ${ }^{8,9}$ sometimes geographically proximal and apparently relevant mobile promotions have been reported as creepy and intrusive to potential shoppers and caused lower intention to make immediate purchases. ${ }^{10}$ The notion of intrusiveness is embedded in perceptions of control, which is known to be a moderator of how interruptions can affect consumers. ${ }^{11}$ When consumers have the choice of ignoring the interruption, many of the negative effects may be alleviated. ${ }^{12}$

As a result, if a marketing message that can be easily ignored interrupts the consumer without demanding immediate action, the negative consequences of interruption may not persist over a period of time. It is also true that a relevant piece of information viewed at an otherwise occupied moment can appear incongruent to the receiver, and incongruent information causes more arousal and elaborate information processing, making it more memorable. ${ }^{13}$ Hence, it seems reasonable to expect that marketing messages that interrupt consumers' activities but are easy to ignore will appear incongruent to customers, become more memorable, not 
cause any negative impressions and potentially translate to more redemptions than if they were not interruptive. In fact, a recent study by Ipsos, ASI $^{14}$ finds that instead of preferring ads that fade into the background of web pages, consumers prefer those that get in their face by taking over their computer screens. Interruptive marketing practices have also demonstrated effects of increased brand recognition, recall and awareness. $^{15,16}$

\section{Data from Midwestern firm}

\section{Message type}

To test the above effects of interruptions in the context of mobile message campaigns on consumers, we analyse field-experiment data collected by a Midwestern firm. In the following sections, we illustrate the role of two different factors, message type and situation type (interruptive or non-interruptive); discuss the influence on coupon redemptions; frame hypotheses for expected findings; illustrate the process of data collection; analyse data and describe findings.

\section{Hypotheses}

The impact of interruptions on behaviour can never be predicted without accounting for the nature of content. Simple SMS coupons contain text messages with a short string of characters: they can be framed in an objective, factual manner, or subjective, descriptive claims. Marketers often design advertisement messages with subjective expressions such as 'delicious juicy steak' or 'excellent gas mileage'. These are mostly impressionistic statements or phrases that are subject to individual interpretation. The opposite is when factual information is used instead, such as ' 5 grams of sugar per serving' or '35 miles per gallon'. The former have been called subjective claims, which contain emotional or subjective claims of both tangible and intangible aspects of a product, ${ }^{17}$ whereas the latter are considered to be more objective claims, that are verifiable by the marketers, consumers or a third party. ${ }^{18}$ Though various terms have been used (objective/factual, subjective/evaluative), objective claims have been generally preferable to consumers because they seem to be 'verifiable'. ${ }^{18}$ Furthermore, consumers may also be more sceptical about subjective claims than objective claims, leading to better memory of the latter.

H1a: Objective messages will show higher recognition scores than descriptive messages

H1b: Objective messages will show higher actual coupon redemptions than descriptive messages

H1c: Objective messages will show higher future purchase intentions than descriptive messages

On the other hand, it is also expected that some amount of incongruity in the situation (such as interruption) can provide enough motivation and arousal to the user to be able to remember, process, positively evaluate and respond to the message. Hence, messages that reach and interrupt the consumer when they are actively engaged will be more likely to be 
Objective and subjective impacts remembered and responded to. For the rest of the paper, messages sent in active situations will represent the interruptive and messages sent in passive situations the non-interruptive messages.

H2a: Messages in active situations will show higher recognition scores than messages in passive situations

H2b: Messages in active situations will show higher redemptions than messages in passive situations

H2c: Messages in active situations will show higher purchase intentions than messages in passive situations

It is expected that interruptions incongruent to the environment will cause heuristic ad processing, and factual or objective messages will be better received in such situations than descriptive or evaluative appeals because it is simpler to process them. Thus, those who are interrupted, that is, receive the message coupons while actively engaged in other tasks, will be more likely to remember, desire and redeem the objective claim coupons, and those who receive the non-interruptive messages in more passive moments will more likely remember, redeem and desire the subjective claim coupons.

In Active Situations,

H3a: Objective messages will show higher recognition scores than Subjective messages

H3b: Objective messages will show higher redemptions than Subjective messages

H3c: Objective messages will show higher future purchase intentions than Subjective messages

In Passive Situations,

H4a: Subjective messages will show higher recognition scores than Objective messages

H4b: Subjective messages will show higher redemptions than Objective messages

H4c: Subjective messages will show higher purchase intentions than Objective messages

\section{Data collection}

Customers of two major national fast food chains were signed up for receiving text coupons on their mobile phones, and users agreed to receive 
between four and six messages a month. Each message contained coupons for redemption at the company outlets. Two types of messages were sent out; the messages contained three types of information: product information (eg burger/ice cream/chicken strips/queso), price information and attribute information (eg weight of the meat, spice content). After 7 days, a $\$ 5$ incentive was declared to have some respondents and non-respondents fill out a 5-minute survey. A sample of 415 responded to this survey.

\section{Sample description}

\section{Stimulus material}

\section{Measures}

The sample of customers who participated in the field experiment was 47 per cent men and 53 per cent women. The age ranged from 18 to 63 , with a mean of 28.25 . They had annual household incomes in a median range of $\$ 20,000-\$ 75,000$. Educationally, 17 per cent had high school or less education, 57 per cent had undergraduate degrees or vocational training, and 25 per cent had graduate education. In addition, 32.8 per cent were married and 92.5 per cent of the respondents were white.

The first set of messages contained subjective ad claims describing the attribute information: 'It's cooling down, but DQ is keepin it HOT! A big, sizzling hot Flame burger with jalapeno bacon for \$1.99! Limit 1 Vld [Midwest DQ] Exp 10/14' and 'Qdoba: Treat yourself to a meal worth \$3.00 FREE incl. Sm Chips with filling and nutritious Queso! Lmt 1 Exp: 3/31 Code: 1201 Vld [individual store info]'. The second set of messages contained objective ad claims saying, 'It's cooling down, but DQ is keepin it HOT! 1/4 lb Flame burger with 3,500 scovilles of hot jalapeno bacon for \$1.99! Limit 1 Vld [Midwest DQ] Exp 10/14' and 'Qdoba: Treat yourself to a meal worth \$3.00 FREE incl. Sm Chips with 4oz Queso that has $9 \mathrm{~g}$ of Protein! Limit 1 Exp: 3/31 Code: 1201 Vld [individual store info]'.

(a) Independent variables

(i) Ad claim objectivity/subjectivity: manipulated between groups

(ii) Interruption: Message received in an active or a passive situation. This variable is not manipulated, but measured.

(b) Dependent variables

(i) Product recognition: a multiple choice question was placed, saying, 'The promoted product was a [...]?' (one correct, three incorrect alternatives).

(ii) Attribute recognition: a multiple choice question was placed, saying, 'The promoted product was described as [...]?' With one fully correct, two partly correct and one completely incorrect alternative.

(iii) Price recognition: a multiple choice question was placed, saying, 'The promoted price was [...]?' With one correct and three incorrect alternatives.

(iv) Recognition accuracy scores: the above three scores were added, leading to scores on a continuum of $0-4$, giving us a 5-point scale.

(v) Future purchase intentions: measured by a single-item question on a scale of 1-7: 'In future, would you be interested in buying other 


\section{Understanding message impact}

\section{Utility for consumer}

products associated with this brand?' $(1-$ strongly disagree to 7 - strongly agree).

(vi) Redemption: Did they redeem the coupon or not.

\section{Model}

The objective of this study is to understand the impact of the type of message (objective versus subjective) and situation (active versus passive) on (1) a customer's propensity to redeem mobile coupons, (2) recognition of the product, price of the product and attributes of the product and (3) an individual customer's future purchase intentions. More specifically, we investigate customer behaviour when customers receive coupons on their mobile devices and focus our attention on understanding three distinct behaviours that are important from a marketer's perspective. The individual customer choice decision, whether to redeem a coupon or not, is a binary choice variable and thus we use logistic regression to model the binary decision. To model a focal customer's recognition or memory of the product, its price and its attributes and the focal customer's future purchase intentions, we take a linear regression approach.

We describe the coupon redemption model wherein we model a customer's choice of redeeming a coupon as a discrete choice variable and adopt the familiar random utility approach. The indirect utility obtained by a customer $i$ from redeeming a coupon, $U_{i}$, is expressed as follows:

$$
U_{i}=V_{i}+\varepsilon_{i}
$$

The representative utility, $V_{i}$, of a customer $i$ redeeming a coupon is given as follows:

$$
\begin{aligned}
V_{i}= & \alpha_{1}+\beta_{1} \text { ObjectiveAd }_{i}+\beta_{2} \text { Active }_{i}+\beta_{3} \text { ObjectiveAd }_{i} * \text { Active }_{i}+\beta_{4} \text { Gender }_{i} \\
& +\beta_{5} \text { Age }_{i}+\beta_{6} \text { Income }_{i}+\beta_{7} \text { Occupation }_{i}+\beta_{8} \text { MaritalStatus }_{i}+\beta_{9} \text { Race }_{i}
\end{aligned}
$$

where ObjectiveAd $_{i}$ is an indicator variable that takes the value 1 if a customer receives an ad with objective information and 0 otherwise, Active $_{i}$ takes the value 1 if a customer is deemed to be in an active situation when he received the ad on his mobile device. Gender $r_{i}$ is the gender of the customer $i$, Age $_{i}$ is the age of customer $i$, Income $_{i}$ is the income level of a customer i. Occupation, MaritalStatus $_{i}$ and Race $_{i}$ are the fixed effects for the occupation, marital status and race of a customer $i$.

The models for memory and future purchase intention are expressed by the following equation:

$$
\begin{aligned}
Y_{i}= & \alpha_{2}+\gamma_{1} \text { ObjectiveAd }_{i}+\gamma_{2} \text { Active }_{i}+\gamma_{3} \text { ObjectiveAd }_{i} * \text { Active }_{i}+\gamma_{4} \text { Gender }_{i} \\
& +\gamma_{5} \text { Age }_{i}+\gamma_{6} \text { Income }_{i}+\gamma_{7} \text { CouponRedemption }_{i}+\gamma_{8} \text { Occupation }_{i} \\
& +\gamma_{9} \text { MaritalStatus }_{i}+\gamma_{10} \text { Race }_{i}+\varepsilon
\end{aligned}
$$

where CouponRedemption ${ }_{i}$ is an indicator variable that takes the value 1 if a customer $i$ redeems the coupon received via the mobile ad and 0 otherwise, $\varepsilon$ is the error term. All the other variables are as defined in equation (1). 


\section{Probability of redemption}

\section{Model-free evidence}

\section{Model estimation}

We model the probability that a customer will redeem a coupon as a binary logit model. Accordingly, the probability that a customer $i$ will redeem the mobile coupon $j$ can be expressed as follows:

$$
p\left(\delta_{i j}=1\right)=\frac{\exp \left(V_{i j}\right)}{1+\exp \left(V_{i j}\right)}
$$

where $\delta_{i j}$ is a customer level choice indicator variable that is equal to 1 if the customer $i$ redeems the coupon $j$ and 0 otherwise.

The likelihood, $L$, can be written as follows:

$$
L\left(\alpha_{1}, \beta\right)=\prod_{i=1}^{n}(P r)^{\delta_{i j}}(1-P r)^{1-\delta_{i j}}
$$

where $p_{i j}$ is the probability that a consumer $i$ will redeem a mobile coupon $j$ (as given by equation (3)). The model is estimated by maximizing the likelihood given in equation (4). The memory and the purchase intention models are linear regressions and are estimated via the maximum likelihood approach.

\section{Results}

The overall redemptions, recognition scores and future purchase intentions of customers in different experimental conditions are summarized in Table 1. From Table 1, we note that objective advertising messages or marketing messages that contain factual content have a greater percentage of coupon redemptions. In particular, objective messages have a 7.02 per cent higher coupon redemption rate than subjective advertising messages. Average recognition, which measures consumers' recognition of the product, its attributes and price, is also significantly higher for objective messages in comparison with subjective messages (average recognition score mean for objective messages $=2.99$ versus mean for subjective marketing messages $=2.46$ ). These summary statistics present model-free evidence that objective messages have a greater coupon redemption rate and also aid in better recall of the products, product attributes and product price.

Table 1: Effect of message type and situation on redemption, recognition and intentions

\begin{tabular}{lccc}
\hline Variable & $\begin{array}{c}\text { Percentage of coupon } \\
\text { redemptions }\end{array}$ & $\begin{array}{c}\text { Average } \\
\text { recognition }\end{array}$ & $\begin{array}{c}\text { Future purchase } \\
\text { intentions }\end{array}$ \\
\hline Objective Ad Message & 33.25 & 2.99 & 6.09 \\
Subjective Ad message & 26.02 & 2.46 & 6.1 \\
Active Situation & 37.59 & 2.74 & 6.1 \\
Passive Situation & 21.69 & 2.67 & 6.09 \\
Objective Ad Messages in Active Situations & 20.96 & 3 & 6.24 \\
Objective Ad Messages in Passive Situations & 12.29 & 2.95 & 5.85 \\
Subjective Ad Messages in Active Situations & 16.63 & 2.51 & 5.98 \\
Subjective Ad Messages in Passive Situations & 9.40 & 2.38 & 6.35 \\
\hline
\end{tabular}




\section{Active situations win out}

\section{Interaction effect}

Effect of message and
situation

\section{Parameter estimates}

\section{Control effects}

Turning our attention to the effect of the situation a consumer is in at the time the marketing message is received, we find from Table 1 that when consumers are engaged in active situations at the moment the mobile message is received, coupon redemption rate is significantly higher than when consumers are engaged in passive situations (37.59 versus 21.69 per cent). Average recognition of the product, attributes and price is also greater when consumers receive mobile coupons in active situations than when they receive coupons in passive situations (2.74 versus 2.67$)$. This leads us to believe that consumers' processing of information is different when they are in active versus passive situations and they are likely to pay more attention to messages when interrupted, that is, in active situations.

Table 1 also provides summary statistics related to the interaction effect between type of message (objective versus subjective message) and type of situation (active versus passive situation). Objective messages that were received in active situations yield a greater number of coupon redemptions than objective messages in passive situations (20.96 versus 12.29 per cent). Furthermore, subjective messages received in active situations also result in more coupon redemptions than subjective messages received in passive situations (16.63 versus 9.4 per cent). In a similar vein, objective messages received when consumers are involved in active situations led to higher average recognition scores spanning product, attribute and price recall variables than the corresponding consumer recognition scores for objective messages received in passive situations (3.0 versus 2.95). For this interaction effect, future purchase intentions were also higher when objective messages were received in active situations (6.24 versus 5.85).

The above discussion related to descriptive statistics from our data provides some model-free evidence for our hypotheses regarding the effect of type of messages and type of consumer situation on consumers' likelihood of coupon redemption, recognition scores and future purchase intentions. We now provide results of our estimation of the models described in the model section that study the effect of message and situation type on consumers' behavioural and recall variables.

As described in the model section, we estimate three models to assess the effect of message type and situation on (1) likelihood of coupon redemption, (2) recognition and (3) future purchase intentions. Before discussing the results from our estimation of these three main models, we estimated a series of alternative models wherein instead of all the variables of the proposed models, we included control variables only and compared the model fit from this model with the ones wherein we add the main effects and the proposed interaction effects in our models. This allows us to assess the model fit of the various models and ensures that the variables that are added to the control variables improve the model fit and thus the performance of the models.

We include several control variables in the models we estimate. These include demographic characteristics of consumers such as gender, age and income level. These control for any differences in coupon redemption, memory and future purchase intentions that may occur across males and females, different age groups and income levels. In addition to these control variables, we also include fixed effects related to consumers' 
occupation, marital status and race. We believe these control effects sufficiently capture differences in response to marketing messages that occur across different segments of population. In the memory and future purchase intention models, we also include a control variable for coupon redemption that controls for any differences in recognition and purchase intentions across consumers who have redeemed the coupon received and the consumers who have not redeemed the coupon received. After controlling for these variables, we are able to examine in a clean manner the main effects of our variables of interest, namely, type of mobile messages and type of consumer situation.

The results of the models that assess performance of the proposed

Model performance improvement

\section{Objective content wins out}

\section{Awareness in active situations} models vis-à-vis the control variables-only models are presented in Table 2. As we can observe from Table 2, the model fit (in terms of log likelihood numbers) improves for all three models (ie coupon redemption, average recognition and future purchase intentions) as we include the main effects and interaction effects that test our hypotheses in an incremental fashion. In other words, results from Table 2 demonstrate that the inclusion of main and interaction effects in control variables-only models helps improve the performance of the models, and that these variables truly help capture the underlying effects of message type and situation on our dependent variables.

We now present results from the estimation of our proposed models. These results are presented in Table 3. Our first set of hypotheses $(\mathrm{H} 1 \mathrm{a}-\mathrm{c})$ state that customers who receive objective messages that contain more factual information as opposed to information that is open to subjective interpretations will exhibit higher coupon redemption rates, demonstrate greater recognition and have increased future purchase intentions. From Table 3, we observe that the coefficients corresponding to the message type (which is coded as 1 if the message received is objective in nature and 0 otherwise) are positive and significant for all three models. Thus, H1a-c are strongly supported. This suggests that consumers exhibit greater positive response to messages with more objective content and may therefore prefer to receive such messages. This finding is also in conformance with the finding from the model-free evidence presented earlier in the paper.

Hypotheses $(\mathrm{H} 2 \mathrm{a}-\mathrm{c})$ state that in active situations, consumers are more likely to respond to mobile coupons and thus are likely to exhibit a greater likelihood of positive behaviours such as coupon redemption, recall and

Table 2: Model fit statistics

\begin{tabular}{lccc}
\hline Model & $\begin{array}{c}\text { Coupon } \\
\text { redemption }\end{array}$ & $\begin{array}{c}\text { Memory } \\
\text { Future purchase } \\
\text { intentions }\end{array}$ \\
\hline Model 1: Control variables only & -505.05 & -650.06 & -672.33 \\
Model 2: Control variables+Main effects only & -478.08 & -636.64 & -658.78 \\
Model 3: Control variables+Main+Interaction effects & -410.32 & -616.55 & -634.66 \\
\hline
\end{tabular}

Note: This table presents the log-likelihood figures of the different models estimated for understanding the performance of the models. 
Table 3: Effect of objective versus subjective messages on coupon redemption, memory and future purchase intentions

\begin{tabular}{|c|c|c|c|c|c|c|}
\hline \multirow[t]{2}{*}{ Independent variable } & \multicolumn{2}{|c|}{ Coupon redemption } & \multicolumn{2}{|c|}{ Memory } & \multicolumn{2}{|c|}{$\begin{array}{l}\text { Future purchase } \\
\text { intentions }\end{array}$} \\
\hline & $\begin{array}{l}\text { Parameter } \\
\text { estimate }\end{array}$ & $\begin{array}{l}\text { Standard } \\
\text { error }\end{array}$ & $\begin{array}{l}\text { Parameter } \\
\text { estimate }\end{array}$ & $\begin{array}{l}\text { Standard } \\
\text { error }\end{array}$ & $\begin{array}{l}\text { Parameter } \\
\text { estimate }\end{array}$ & $\begin{array}{c}\text { Standard } \\
\text { error }\end{array}$ \\
\hline Intercept & $0.642^{* * *}$ & 0.0771 & $2.4256^{* * *}$ & 0.1816 & $6.2978 * * *$ & 0.2095 \\
\hline Objective Ad Message & $0.1497 * * *$ & 0.0402 & $0.6289 * * *$ & 0.1888 & $0.5227^{* *}$ & 0.2024 \\
\hline Active Situation & $0.0585^{*}$ & 0.0293 & $0.1292 *$ & 0.0643 & $0.3448^{*}$ & 0.1755 \\
\hline $\begin{array}{l}\text { Objective Ad Messa- } \\
\text { ge*Active Situation }\end{array}$ & $0.0348^{*}$ & 0.01591 & $0.0943 *$ & 0.0433 & $0.7187^{* *}$ & 0.2491 \\
\hline Gender & $-0.1088^{*}$ & 0.0475 & $-0.2327^{*}$ & 0.1118 & -0.1565 & 0.1201 \\
\hline Age & 0.0001 & 0.0002 & -0.0002 & 0.0006 & 0.0001 & 0.0006 \\
\hline Income Level & -0.0159 & 0.0168 & 0.0284 & 0.0396 & -0.0191 & 0.0424 \\
\hline Coupon Redemption & - & - & $0.1664 *$ & 0.0755 & $0.328^{* *}$ & 0.1236 \\
\hline $\begin{array}{l}\text { Occupation Fixed } \\
\text { Effects }\end{array}$ & Yes & & Yes & & Yes & \\
\hline $\begin{array}{l}\text { Marital Status Fixed } \\
\text { Effects }\end{array}$ & Yes & & Yes & & Yes & \\
\hline Race Fixed Effects & Yes & & Yes & & Yes & \\
\hline
\end{tabular}

${ }^{* * *} p \leqslant 0.001,{ }^{* *} p \leqslant 0.01, * p \leqslant 0.05$.

\section{Objective messages in active situations}

\section{Redemption and recognition}

future purchase intentions. Our argument for this set of hypotheses rests on the premise that in active situations, consumers may be more stimulated and thus may be more aware of information presented to them. This increased awareness and arousal can lead to more positive behaviours that a marketer may be able to take advantage of by sending appropriate messages to consumers in such situations. We indeed observe such effects, as shown in Table 3 . The coefficients corresponding to the variable active message are indeed positive and significant for our three models, thus providing strong support for our second set of hypotheses.

Our final set of hypotheses relate to the interaction effects between message type and individual situation $(\mathrm{H} 3 \mathrm{a}-\mathrm{c})$. In particular, we hypothesize that effect of objective messages is greater when consumers receive these messages in more active situations. We indeed find support for this set of hypotheses. Our results from Table 3 suggest that the effect of objective messages is enhanced when these messages are consumed in active situations. The interaction coefficients between objective message and active situation are positive and significant for all three models. Since both message type and situation are indicator variables that take the value 1 for objective message and active situation and 0 otherwise, we cannot include interaction effects between subjective message and passive situation, which could lead to multicollinearity issues and, hence, we are unable to test hypotheses $\mathrm{H} 4 \mathrm{a}-\mathrm{c}$ using our models.

However, we can gather some insight from the summary statistics table, Table 1, on the interaction between subjective messages and passive situations. We find limited evidence for this set of hypotheses from the information presented in Table 1. In passive situations, while subjective messages can lead to greater future purchase intentions than objective messages, it is the objective messages that yield greater coupon 
redemption rates and average recognition scores. Thus, we have model-free evidence for only $\mathrm{H} 4 \mathrm{c}$, while $\mathrm{H} 4 \mathrm{a}-\mathrm{b}$ are not supported in our data.

Purchase intentions

\section{Clear guide on message type}

\section{Campaign timing}

\section{Positive effects of interruption}

As for the results regarding our control variables, we find no differences across age and income level across the three models. Gender is significant for coupon redemption and memory models while it is insignificant for future purchase intention models. Coupon redemption is positive and significant for memory and future purchase intentions, which means consumers who have redeemed the received coupon are likely to have better recognition scores regarding product, attributes and price, and are also likely to report positive future purchase intentions.

In sum, we find very strong evidence for the effect of objective messages on coupon redemption, memory and future purchase intentions. We also find that interruptive messages received in active situations result in much better behavioural outcomes from the marketer's perspective. In addition, we also find support for the interaction effect between the type of message and situation type. These results are supported using two different methodologies, that is, we not only present model-free evidence but also supplement this evidence by using econometric models that control for several consumer demographic characteristics, which can explain differences in consumers' preferences and behaviours. From a marketing manager's perspective, our results help provide clear guidelines on what type of messages are likely to be most effective and which consumer situations are likely to result in better outcomes for the firm. We discuss the implications of our results in detail below.

\section{Discussion and implications}

At a micro level, the above findings indicate that managers need to better understand and design their messaging campaigns so that more analytic and factual content is provided to their customers for higher effectiveness. The results show that customers are more receptive to detailed information content, and also remember such information better. This implies better outcomes for awareness campaigns on product features, or new product launches. The interruptions also seem to perform better, demonstrating that the campaign timing for sending out messages does not need to be restricted to leisure times of the target audience.

However, at a broader level, we examine the role played by these interruptive messages in the context of the relationship between the firm and their customers. In this information age, most consumers prefer custom content and say they are more likely to buy from a company that understands their needs. As a result, most brands are also in the process of reducing their outbound push marketing efforts. Despite those market trends, we find positive effects of interruption in mobile coupon campaigns by conducting the study among loyalty customers. The subjects were loyal customers of fast food brands who agreed to receive four to six messages a month, they had a certain level of mental preparedness to be disrupted, and being loyal customers those interruptions were deemed permissible as they originated from a known source. 
Loyalty context
In the process of trying to improve their customers' lifetime values, brands often deliver information they want and need, but they also thrill, delight and surprise customers with information, features and functions customers did not know about. If they deliver these interruptions, novelties and surprises within the context of a loyal relationship, interruptions seem to work positively even in mobile marketing campaigns. Past studies have found that interruptions are less likely to work if they are perceived as intrusive (location-based messages) because they are viewed as a product of uninvited surveillance. However, this study's findings show that when messages are directed to loyal customers who have been enroled in a programme, the interruptions are no longer 'uninvited' and can be fruitful for improving memory of products, deals promoted, redemption rates of the campaign and future purchase intentions of the brand.

\section{References}

1. O'Brien, B. (2014) 'Explosive growth in mobility and location-based marketing, Cisco Blog Post', 30 April, http://blogs.cisco.com/wireless/explosive-growth-in-mobility-and-locationbased-marketing, accessed 21 February 2015.

2. O’Malley, G. (2014) 'Location-based mobile ads forecast to Hit \$10.8B in 2017', Mobile Marketing Daily, 16 January, http://www.mediapost.com/publications/article/217520/locationbased-mobile-ads-forecast-to-hit-108b-i.html, accessed 20 February 2015.

3. Coraggio, L. (1990) 'Deleterious effects of intermittent interruptions on the task performance of knowledge workers: A laboratory investigation'. Unpublished doctoral dissertation, University of Arizona, Tucson, AZ.

4. Normon, D.A. and Bobrow, D.G. (1975) 'On data-limited and resource-limited processes', Cognitive Psychology, Vol. 7, No. 1, pp. 44-64.

5. Cho, C.H. and Hongsik, J.C. (2004) 'Why do people avoid advertising on the internet?', Journal of Advertising, Vol. 33, No. 4, pp. 89-97.

6. Edwards, S.M., Li, H. and Lee, J.H. (2002) 'Forced exposure and psychological reactance: Antecedents and consequences of the perceived intrusiveness of pop-up ads', Journal of Advertising, Vol. 31, No. 3, pp. 83-96.

7. Acquisti, A. and Spiekermann, S. (2011) 'Do interruptions pay off? Effects of interruptive ads on consumers' willingness to pay', Journal of Interactive Marketing. Vol. 25, No. 4, May, pp. 226-240.

8. Grewal, D., Marmorstein, H. and Sharma, A. (1996) 'Communicating price information through semantic cues: The moderating effects of situation and discount size', Journal of Consumer Research, Vol. 23, No. 2, September, pp. 148-155.

9. Hoch, S.J. and Deighton, J. (1989) 'Managing what consumers learn from experience', Journal of Marketing, Vol. 53, No. 2, April, pp. 1-20.

10. Banerjee, S. and Dholakia, R.R. (2008) 'Does location based advertising work?', International Journal of Mobile Marketing. Vol. 3, No. 2, December, pp. 68-74.

11. Ariely, D. (1999) 'Controlling the information flow: The role of interactivity in consumers' decision making and preferences'. Cambridge, UK: Massachusetts Institute of Technology. Working paper.

12. Xia, L. and Sudharshan, D. (2002) 'Effects of interruptions on consumer online decision processes', Journal of Consumer Psychology, Vol. 12, No. 3, pp. 265-280.

13. Mandler, G. (1982) 'The structure of value: Accounting for taste' in Clarke, M. S. and Fiske, S. T., (eds) Affect and Cognition: The 17th Annual Carnagee Symposium, Lawrence Erlbaum Associates, Hillsdale, NJ: pp. 3-36.

14. Shields, M. (2014) 'People prefer big, interruptive, Web Ads', Adweek, 24 January, http://www. adweek.com/news/advertising-branding/people-prefer-big-interruptive-web-ads-155165, accessed 22 February 2015.

15. Barry, T.E. and Howard, D.J. (1990) 'A review and critique of the hierarchy of effects in advertising', International Journal of Advertising, Vol. 9, No. 2, pp. 121-135. 


\section{The art of mistiming 凉}

16. Yoo, C.Y., Kim, K. and Stout, P.A. (2004) 'Assessing the effects of animation in online banner advertising: Hierarchy of effects model', Journal of Interactive Advertising, Vol. 4, No. 2, pp. 7-17.

17. Holbrook, M.B. (1978) 'Beyond attitude structure', Journal of Marketing Research, Vol. XV, No. 4, November, pp. 545-556.

18. Darley, W.K. and Smith, R.E. (1993) 'Advertising claim objectivity: Antecedents and effects', Journal of Marketing, Vol. 57, October, pp. 100-113. 